\title{
Beobachtung des Mercurdurchganges am 6. Mai 1878 in Breslau.
}

Der Himmel war hier zwar wahrend der ganzen Beobachtungszeit klar und fast ganz wolkenlos, die Luft jedoch stetig tremulirend und fur die Beobachtung ungünstig. Es wur nicht für möglich zu erachten, an dem Sonnen- oder Mercursrande Bruchtheile einer Bogensecunde zu messen oder demgemäss die Zeitmomente genauer als vielleicht bis auf $15^{s}$ anzugeben Ich beobachtete im Thurme an dem 5fuussigen Bardou'schen Fernrohr, das mit einem vorzüglichen bläulichen Sonnenglase versehen war, folgende Zeiten:

m. Br. Zt.

Aeussere Berührung (vielleicht um mehr als $15^{8}$ zu spat)

$4^{\mathrm{l}} 1 \mathrm{gm}^{\mathrm{m}} 42^{\mathrm{B}} 6$

Mercur halb eingetreten

4.20 .54 .6

Innere (geometrische) Berithrung

4.22 .17 .6

Innere Berührung (völlige Trennung durch einen lichten $\mathrm{Z}$ wischenr.) 4.22 .40 .6

Herr Dr. Neugebauer, jetzt Lehrer an der hiesigen K. Gewerbeschule, beobachtete ein Stockwerk tiefor im grossen Saale an dem 41/2 Fuss Fraunhofer:
Aeussere Berührung $\quad 4^{\mathrm{h}} 19^{\mathrm{m}} 38_{\mathrm{sg}}$

Innere Berührnng (vőll. Trennung) 4.22.40.4

Herr Rostalski assistirte bei meiner Beobachtung durch Aufschreiben, da ich es als möglich betrachtet liatte, ausser den Zeitmomenten auch einige physische Wahrnehmungen notiren lassen zu können. Indess war es bei der Unruhe der Luft unmöglich, irgend etwas genaueres uber den Vorlauf bei der Trennung der Bilder oder etwaige Indicien einer Mercurs-Atmosphire wahrzunehmen. Ferner habe ich in Erinnerung an die im 10.'Bande der Astr. Nachr. S. 195 beschrie. bene, hier in Schlesien von Schenck gesehene und als einen Trabanten des Mercur gedeutete Erscheinung auch auf die năchste Umgebung des Planeten geachtet, jedoch weder daneben, noch sonst auf der Sonnenoberfluche irgend einen Flecken wahrgenommen.

Breslau 1878, Mai 17.

Beobachtung des Mercurdurchganges am 6. Mai 1878 auf der Prager Sternwarte.

Der Mercurdurehgang konnte unter günstigen atmosplärischen Verbältnissen beobachtet werden. $\mathrm{Da}$ jedoch mit dem Steinheil'sehen Fernrobr von 6 Zoll Oeffnung nur Beobachtungen nahe am Meridian gemacht werden können, so blieben nur zwei kleinere Fernuöhre, namlich ein Fraunhofer'sches von 4Z Linien Oeffnung und ein Voigtlander'sches 'von 27 Linien Oeffinung zur Vertugung. An ersterem beubachtete Herr Dr. Seydler, an letzterem Herr Ed. Wenzel, wie folgt:

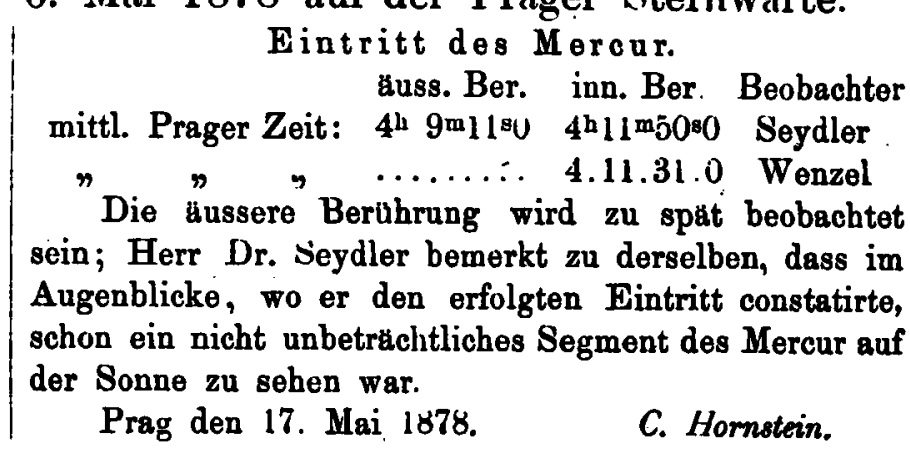

\section{Anzeige.}

Zu verkaufen ein Universalinstrument von Fennel in Cassel. Kreise 6 zöll. Vier Microscope. Ablesung $0^{\prime \prime} \bar{\jmath}$. Eine Libelle test am Microscopentrager, eine Andere zum Aufsetzen. Fernrohr 15 Lin. Oeffng., 10 Z. Focus. Versicherungsrohr, Schrankehen und Kasten. Preis 800 M. Bezahlt 1350 M. Dies Instrument ist so gut wie neu. Nalieres in Dresden beim Mechaniker Suhadewell:

\section{Inhalt:}

Zu Nr. 2201. George Rümker. Beobachtungen der Cometen von 1877. 257. - E. Becker. Resultate aus den Beobacintungen von 11 Polsternen am grossen Meridiankreise der Berliner Sternwarte. 263. - Ormond Stome. On Personal Equation in Double Star Observations. 27I.

Zu Nr. 2202. F. Frans. Mars-Opposition 1877. 273. - W. Doberck. Values of $M$ tabulated for different with argument E. 275. -- $W$. Doberck. Values of $E$ tabulated for different 1 with argument $M .279$. $-N$. Dunér. Beobachtung des Mercurdurchganges vom 6 . Mai 1878 auf der Sternwarte zu Lund. 283. - William F. Denning. Meteor showers visible during August 6-12 with Radiant points eastward of the Perseids (Ra. $44^{\circ}$ Dec. $56^{\circ}+$ ). 283. - F. G. Galle. Beobachtung des Mereurdurchganges am 6. Mai in Breslau. 287. $-C$. Hornstein. Beobachtung des Mercur-Durchganges am 6. Mai 1878 anf der Prager Sternwarte. 287. - Anzeige. 287 